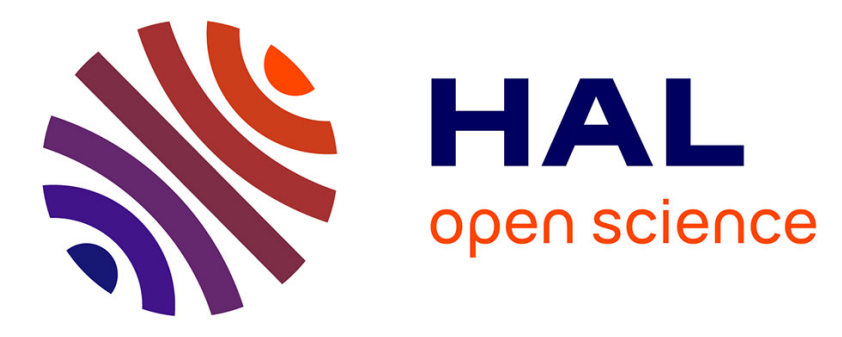

\title{
Comparative gene transfer between cationic and thiourea lipoplexes
}

\author{
Marie Breton, Jeanne Leblond, Johanne Seguin, Patrick Midoux, Daniel \\ Scherman, Jean Herscovici, Chantal Pichon, Nathalie Mignet
}

\section{To cite this version:}

Marie Breton, Jeanne Leblond, Johanne Seguin, Patrick Midoux, Daniel Scherman, et al.. Comparative gene transfer between cationic and thiourea lipoplexes. The Journal of Gene Medicine, 2009, 12 (1), pp.45-54. 10.1002/jgm.1417 . hal-02512540

\section{HAL Id: hal-02512540 https://hal.science/hal-02512540}

Submitted on 20 Mar 2020

HAL is a multi-disciplinary open access archive for the deposit and dissemination of scientific research documents, whether they are published or not. The documents may come from teaching and research institutions in France or abroad, or from public or private research centers.
L'archive ouverte pluridisciplinaire HAL, est destinée au dépôt et à la diffusion de documents scientifiques de niveau recherche, publiés ou non, émanant des établissements d'enseignement et de recherche français ou étrangers, des laboratoires publics ou privés. 


\section{Comparative gene transfer between cationic and}

\section{thiourea lipoplexes}

Marie Breton ${ }^{1}$, Jeanne Leblond ${ }^{2}$ PhD, Johanne Seguin ${ }^{1}$, Patrick Midoux ${ }^{3}$ PhD, Daniel Scherman ${ }^{1}$ PhD, Jean Herscovici ${ }^{4}$ PhD, Chantal Pichon ${ }^{3}$ PhD and Nathalie Mignet ${ }^{1}$ PhD.

${ }^{1}$ Inserm, U640, CNRS, UMR8151, Unité de Pharmacologie Chimique et Génétique, France; Université Paris Descartes, Faculté de Pharmacie, F-75270 Paris, France.

${ }^{2}$ Canada Research Chair in Drug Delivery, Faculty of Pharmacy, University of Montréal, P.O. Box 6128, Downtown Station, H3C 3J7 Montreal, Quebec, Canada.

${ }^{3}$ Centre de Biophysique Moléculaire CNRS UPR 4301, Université de Orléans, INSERM, rue Charles Sadron, F-45071 Orléans Cedex 2, France.

4 Inserm, U640, CNRS, UMR8151, Unité de Pharmacologie Chimique et Génétique, Ecole Nationale Supérieure de Chimie de Paris, 11, rue Pierre et Marie Curie, F-75005 Paris, France.

This work was conducted in Paris, France.

Correspondence should be addressed to Nathalie Mignet, Université Paris Descartes, 4 avenue de l'observatoire, 75005, Paris, France. Phone: +33(0)153739581 (or 9566). Fax: +33 (0)143266918. Email: nathalie.mignet@parisdescartes.fr

Short title: Gene Transfer by Neutral and Cationic Lipoplexes. 


\section{ABSTRACT}

Background. We have previously developed lipopolythiourea lipids, as neutral DNA condensing agents for systemic gene delivery. Optimization of the lipopolythiourea structure led to efficient transfecting agents. To further evaluate these lipids, we investigated the internalization process of the thiourea lipoplexes and their intracellular mechanism of transfection, and compared it to that of cationic lipoplexes.

Methods. MTT test was used for cytotoxicity assessment. Transfection efficiency was determined by luciferase read-out. Permeation to propidium iodide and EGFP was evaluated by flow cytometry. Kinetics of internalisation and DNA release were monitored by confocal microscopy with labelled DNA. Endocytosis inhibitors were used to study the mechanisms of lipoplex internalisation.

Results. Although thiourea/DNA complexes exhibit a level of transfection almost similar to the one of cationic complexes, the thiourea lipoplexes were shown to be 6 times less internalized. Complexes were able to permeabilise the cytoplasmic membrane to $30 \mathrm{kDa}$ molecules. Finally, DNA was shown to be released in less than 10 minutes in the cellular cytoplasm versus 30 minutes for cationic lipoplexes.

Conclusions. Despite a weaker internalisation as compared to cationic lipids, the thiourea lipoplexes were able to transfect cells at a similar level thanks to its greater ability to destabilise the cytoplasmic membrane and release DNA

Key words: neutral lipoplexes, cationic lipoplexes, membrane binding, internalization, endocytosis, transfection. 


\section{INTRODUCTION}

Synthetic systems for DNA delivery mostly involve ionic interactions. Cationic lipids and polymers have been developed in order to favour strong interaction with DNA phosphates anionic moieties and to form stable structures in which DNA is protected from nuclease degradation. This cationic charge also promotes the cell interaction and uptake[1]. There is conclusive evidence that both complexes made from lipids (lipoplexes) and complexes made from polymers (polyplexes) enter cells via endocytosis[2],[3]. However, this endocytosis can use several distinct pathways such as clathrin mediated endocytosis (or CME), caveolae mediated endocytosis or macropinocytosis. Many experiments have shown that CME is implied in the endocytosis of lipoplexes[4] but the role of the other pathways remains poorly defined. Polyplexes might also use more than a single pathway such as clathrin mediated endocytosis and macropinocytosis[5] or caveolae mediated endocytosis[6],[7]. It is of major importance to elucidate the internalization process, in particular to identify if the complexes need to escape endosomal structures. In such a case, destabilizing fusogenic lipids or peptides should be introduced in the complexes to increase endosomal escape.

A few years ago, we chose to develop original lipids able to compact DNA through hydrogen binding. We hypothesized that uncharged lipids would provide an easier DNA liberation into the cells as compared to cationic lipids, and would limit unspecific protein interactions for in vivo delivery. We used thiourea functions because of their ability to form strong hydrogen bonds with ionic species such as phosphates[8] and introduced three of these functions on a lipid to form a lipopolythiourea[9]. Since then, the synthesis of numerous lipopolythioureas of various lipid lengths bearing different spacers and head moieties has allowed us to define an optimized hydrophobic/hydrophilic balance providing easy formulating lipids able 
to transfect cells efficiently[10],[11]. Although these complexes are able to achieve transfection levels similar to cationic lipoplexes, their drastic difference with cationic entities requires further investigation on their mechanism of action.

In the present work, we investigated the internalization and intracellular trafficking of thiourea lipids and compared them to cationic complexes. As thioureas lipid/DNA complexes are globally uncharged at physiological $\mathrm{pH}$, we suspected that their uptake would be less efficient than that of polyamine based lipoplexes. Moreover, as thioureas are suspected to interact with the phosphates of DNA by hydrogen bonds, we expected them to release DNA more efficiently than in the case of ionic mediated complexes. To evaluate these two potential properties that would allow thiourea lipoplexes to lead to transfection, we thus compared the thiourea lipid DDSTU (DD for didecyl, $\mathrm{S}$ for the serine based linker, TU for its thiourea moiety) and the lipopolyamine DMAPAP (Di-Miristyl AminoPropyl AminoPropyl) based complexes (Figure 1) in terms of cell internalisation and kinetics of DNA release, cytotoxicity and transfection.

Figure 1 Structures of the lipids used in this study: the polythiourea DDSTU (DD for didecyl, S for the serine based linker, TU for its thiourea moiety) and the lipopolyamine DMAPAP (DiMiristyl AminoPropyl AminoPropyl). 


\section{MATERIALS AND METHODS}

The cationic lipid whose name according to the nomenclature is $2-\{3-[$ bis-(3-aminopropyl)-aino]-propylamino $-N$-ditetradecylcarbamoyl methyl-acetamide or RPR209120 that we called DMAPAP was described in the supporting information of ref [12] DDSTU was synthesized according to previously reported procedures[10]. All chemicals were purchased from Sigma Aldrich (Saint Louis, USA) unless otherwise stated. Dioleoylphosphatidylethanolamine (DOPE) was purchased from Avanti Polar lipids, Inc. (Alabama, US).

\section{Cell lines}

B16 murine cells were grown as monolayers incubated at $37^{\circ} \mathrm{C}$ in a humidified atmosphere of $5 \% \mathrm{CO}_{2}$ into Dulbecco's modified Eagle's medium (DMEM) (Gibco, Invitrogen, France) supplemented with L-glutamine $(29.2 \mathrm{mg} / \mathrm{mL})$, penicillin (50 units $/ \mathrm{mL})$, streptomycin (50 units $/ \mathrm{mL}$ ), and $10 \%$ foetal bovine serum.

Human epithelial ovarian carcinoma (HeLa) cell lines (CCL2, ATCC, Rockville MD, USA) and HeLa-EGFP cells expressing constitutively the enhanced green fluorescent protein (EGFP) were routinely grown as monolayers incubated at $37^{\circ} \mathrm{C}$ in a humidified atmosphere of $5 \% \mathrm{CO}_{2}$. $\mathrm{HeLa}-$ EGFP cell clone were obtained by transfection of HeLa cells with pEGFP (pEGFPemd-cmv, $4.797 \mathrm{~kb}$, Packard, Meriden, CT, USA) and selection under geneticine. The clone was isolated by cell sorting (FACSVantage, Becton Dickinson, Grenoble, France). Cells were maintained by regular passage respectively in Dulbecco's modified Eagle's medium (DMEM) (Gibco, Invitrogen, France) supplemented with $10 \%$ heat-inactivated foetal bovine serum (FBS) and 100 units/mL penicillin and 50units/mLstreptomycin each (Gibco, Invitrogen, France). Cells were free from mycoplasma as evidenced by bis-benzimidazole staining [13]. 
The Eahy 926 is a stable, easily maintained endothelial cell line derived from the fusion of human umbilical vein endothelial cells (HUVEC) and A549 cells. Eahy 926 cells were grown as monolayers incubated at $37^{\circ} \mathrm{C}$ in a humidified atmosphere of $5 \% \mathrm{CO}_{2}$ into Dulbecco's modified Eagle's medium (DMEM) (Gibco, Invitrogen, France) supplemented with L-glutamine (29.2 $\mathrm{mg} / \mathrm{mL}$ ), penicillin (50 units/mL), streptomycin (50 units/mL), and 10\% foetal bovine serum.

J774 is a murine macrophage cell line established from a tumour that arose in a female $\mathrm{BALB} / \mathrm{c}$ mouse. $\mathrm{J} 774$ cells were grown as monolayers incubated at $37^{\circ} \mathrm{C}$ in a humidified atmosphere of $5 \% \mathrm{CO}_{2}$ into Dulbecco's modified Eagle's medium (DMEM) (Gibco, Invitrogen, France) supplemented with L-glutamine $(29.2 \mathrm{mg} / \mathrm{mL})$, penicillin (50 units $/ \mathrm{mL})$, streptomycin (50 units/mL), and $10 \%$ foetal bovine serum.

\section{Liposome preparation}

The DDSTU was suspended via an ethanolic injection protocol. DMAPAP/DOPE (1/1) was prepared via the same method. Lipids (and colipids if necessary) were dissolved in ethanol and were added dropwise to ten volumes of water under vigorous agitation. The mixture was stirred overnight and then evaporated under reduced pressure at room temperature to obtain a fairly concentrated solution of liposomes. As an example, DDSTU ( $3 \mathrm{mg}, 4 \mu \mathrm{mol})$ was dissolved in $300 \mu \mathrm{L}$ ethanol. This solution was added dropwise into $5 \mathrm{~mL}$ of stirred filtered water. The mixture was stirred overnight, and then evaporated under reduced pressure at room temperature to obtain a clear suspension of DDSTU at about $10 \mathrm{mM}$ concentration. 


\section{Plasmid preparation}

Plasmid pVax 2 was used for all experiments. $\mathrm{pVax} 2$ is a derivative of the commercial plasmid pVax1 (InVitrogen), which was digested with the restriction enzymes HincII and BamHI to excise the promoter. The plasmid was then blunted with the Klenow fragment, dephosphorylated with alkaline phosphatase, pCMVbeta (Clontech), and was digested with EcoR1 and BamHI to excise the CMV promoter. The CMV promoter was blunted with Klenow enzyme and ligated into the blunted pVax1 to give pVax2. The plasmid pXL3031 was digested with EcoRI and BamHI and then treated with the Klenow fragment to produce a blunted fragment containing the luciferase cDNA. This fragment was ligated into pVax2 after EcoRV digestion and phosphatase alkaline dephosphorylation to give the pVax21- Luc.[14]

\section{DNA/lipid complex preparation}

Plasmid (100 $\mu \mathrm{L}, 0.02 \mathrm{~g} / \mathrm{L}$ in $\left.\mathrm{H}_{2} \mathrm{O}\right)$ was added dropwise with constant vortexing to various amounts of thiourea or cationic liposomes (in $100 \mu \mathrm{L} \mathrm{H}_{2} \mathrm{O}$ ). TU/P indicates the ratio in nanomoles of thiourea function (2 per lipid) versus nanomoles of DNA phosphates.

\section{Gel retardation experiments}

Compaction of DNA was verified by loading $15 \mu \mathrm{L}$ of the samples $(0.1 \mu \mathrm{g}$ DNA) on an agarose gel ( $0.8 \%$ in a TAE buffer) after addition of $5 \mu \mathrm{L}$ of bromophenol blue. The gel was run at $80 \mathrm{~V} / \mathrm{cm}$. DNA was revealed with ethidium bromide and visualized under UV light. 


\section{Size measurement}

Particle diameter was determined by dynamic light scattering on a Zeta Sizer NanoSeries Malvern (Malvern Instruments, France). The concentration of the samples was approximately 0.1 $\mathrm{mM}$ in $\mathrm{H}_{2} \mathrm{O}$.

\section{Phase transition of the lipoplexes as a function of the $\mathrm{pH}$}

A $2.5 \mathrm{mM}$ stock solution of Nile Red was prepared in ethanol. Lipoplexes of DDSTU at ratio $\mathrm{TU} / \mathrm{P}=40$ and $\mathrm{DMAPAP}$ at ratio $\mathrm{N} / \mathrm{P}=4$ were prepared at $\mathrm{pH} 6.7$ in a $5 \mathrm{mM}$ MES/HEPES/sodium acetate buffer and $10 \mu \mathrm{M}$ Nile Red at a $1 \mathrm{mM}$ final concentration. The lipoplexes were then freeze/thawed 5 times. The Nile Red emission maximum was determined at different $\mathrm{pH}$ values, using a protocol in which the $\mathrm{pH}$ was first lowered step by step to acidic $\mathrm{pH}$ (around 3), then raised to $\mathrm{pH}$ 6.7, and subsequently increased step by step from $\mathrm{pH} 6.7$ to approximately $\mathrm{pH}$ 8.5. Nile Red fluorescence was measured on a Varian spectrofluorimeter at $25^{\circ} \mathrm{C}$. The excitation wavelength was set at $550 \mathrm{~nm}$ and the fluorescence emission was recorded from 550 to $700 \mathrm{~nm}$ at $5 \mathrm{~nm}$ intervals. The wavelength of the maximal emission ( $\lambda$ max emission) of Nile Red was calculated using a 4 parameters log-normal fit.

\section{Cytotoxicity}

Murine B16 melanoma cells were grown as described above. Exponentially growing B16 cells were plated onto 96-well plates at 5000 cells per well in $100 \mu \mathrm{L}$ of culture medium. Twenty-four hours after plating, $100 \mu \mathrm{L}$ of medium with the DDSTU lipid or the DMAPAP lipid was added at different concentrations to the wells (in triplicate) containing the cells and incubated for $48 \mathrm{~h}$ at $37{ }^{\circ} \mathrm{C}$ and $5 \% \mathrm{CO}_{2}$. After the $48 \mathrm{~h}$, cell viability was assayed using the MTT test [15] and 
absorbance was read at $562 \mathrm{~nm}$ in a microplate reader (BioKinetics Reader, EL340). Appropriate controls with DMEM only and MTT were run to substract background absorbance. Results are presented as percent of controls cells. The concentration of the lipid that inhibited cell viability by $50 \%$ (inhibitory concentration for $50 \%$ of cells, or $\mathrm{IC}_{50}$ ) was determined using the GraphPad Prism software. Results are presented as means \pm SEM of 6 independent experiments each run in triplicate.

\section{Transfection method}

The murine melanoma cell line B16 was cultured in Dulbecco's modified Eagle's medium containing $10 \%(\mathrm{v} / \mathrm{v})$ fetal bovine serum and $100 \mu \mathrm{g} / \mathrm{ml}$ penicillin/streptomycin (GibcoBRL, Life Technology, Merelbeke, Belgium) with $5 \% \mathrm{CO}_{2}$ at $37^{\circ} \mathrm{C}$. One day before transfection, cells were treated with trypsin and deposited into 24-wells plates (45000 cells / well) and incubated $24 \mathrm{~h}$ at $37^{\circ} \mathrm{C} .50 \mu \mathrm{L}$ of DDSTU/DNA or DMAPAP/DNA (corresponding to $0.5 \mu \mathrm{g}$ DNA) complexes were loaded on each well and the plates were incubated at $37^{\circ} \mathrm{C}$ for $24 \mathrm{~h}$ in $1 \mathrm{~mL} \mathrm{DMEM}+10 \%$ FBS. Then the cells were washed twice with PBS and treated with $200 \mu \mathrm{L}$ of a passive lysis buffer (Promega, Madison, WI, USA). After $15 \mathrm{~min}$, the cells were centrifuged for 5 min at 1200 r/min. $10 \mu \mathrm{L}$ of supernatant and $10 \mu \mathrm{L}$ of iodoacetamide were deposed on a 96 -well plate which was incubated at $37^{\circ} \mathrm{C}$ for $1 \mathrm{~h}$. Protein quantification was performed with the Biorad assay kit (Hercules, CA, USA) and reported to the BSA taken as a reference curve. Luciferase activity was quantified using the Luciferase quantitation assay kit (Promega, Madison, WI, USA). On $10 \mu \mathrm{L}$ of the lysed cells, $50 \mu \mathrm{L}$ of the luciferin substrate was injected via an injector and the absorbance was read immediately at $563 \mathrm{~nm}$ on a Wallac Victor 21420 Multilabel Counter Perkin Elmer. Results are presented as means \pm SEM of the experiments each run in triplicate. SEM 
corresponds to the standard error of the mean define as the standard deviation divided by the square root of sample size.

To test of the effect of endocytosis inhibitors, 1 hour prior transfection, the medium was supplemented by DMEM+10\% FBS + Methyl-beta-cyclodextrine (M $\beta C D)$ 10mM or DMEM + $10 \%$ FBS + 5-(N-ethyl-N-isopropyl)amirolide (EIPA) $100 \mu \mathrm{M}$ or DMEM + 10\% FBS + sucrose 0,45M. The medium was then rinsed and replaced by the lipoplexes diluted in DMEM+10\% FBS. Results are presented as means \pm SEM of the experiments each run in triplicate.

\section{Binding and internalization studies}

Two days before experiments, HeLa cells were seeded at $1 \times 10^{5}$ cells/wells in $24-w e l l s$ plastic culture plate and the transfection was performed with lipoplexes prepared extemporaneously. Plasmid DNA was labelled with the Label IT Cy5 nucleic acid labelling (MIRUS, Madison, WI, USA) at 1:2 reagent/pDNA weight ratio. The Label IT Labelling reaction was carried out according to manufacturer's instructions. For the binding experiments, cells were first incubated for $30 \mathrm{~min}$ at $4^{\circ} \mathrm{C}$ prior transfection. Cells were then incubated during indicated times with thiourea lipoplexes at a ratio $\mathrm{TU} / \mathrm{P}=40$ or cationic lipoplexes at a ratio $\mathrm{N} / \mathrm{P}=4$ made with $2 \mu \mathrm{g}$ of Cy5-labelled plasmid at either $4^{\circ} \mathrm{C}$ or at $37^{\circ} \mathrm{C}$.

For the fluorescence measurement, cells were scraped gently from the culture wells and extensively washed with ice-cold PBS. Following incubation at $37^{\circ} \mathrm{C}$, cells were cooled and extensively washed with ice-cold PBS before harvested by trypsin treatment. The cell pellets were resuspended in PBS containing $15.2 \mathrm{mM} \mathrm{NaF}$ and $0.2 \%$ phenoxyethanol. The fluorescence intensity of the cell suspension was recorded with a LSR flow cytometer (Becton Dickinson, 
Sunnyvale, CA). The fluorescence of Cy5-labelled plasmid was recorded at $\lambda$ exc of $633 \mathrm{~nm}$ and 10000 events were counted in each sample. For all data shown, the mean autofluorescence intensity (background fluorescence) of control cells has been subtracted from the mean fluorescence intensity of treated cells. Data are the mean of 3 separated experiments made in duplicate.

\section{Permeabilization experiments}

Trypsinized EGFP-HeLa cells were washed and suspended $\left(10^{7}\right.$ cells $\left./ \mathrm{mL}\right)$ in phosphate buffer saline (PBS). Samples were composed of $50 \mu \mathrm{L}$ of this cell suspension in $400 \mu \mathrm{L}$ of sheath fluid buffer. DDSTU lipoplexes at ratio TU/P $=40$ or DMAPAP lipoplexes at ratio N/P $=4$ were added to the samples and incubated for indicated times at $37^{\circ} \mathrm{C}$. Just before measurement, $10 \mu \mathrm{L}$ of propidium iodide $(5 \mu \mathrm{g} / \mathrm{mL})$ was added to the sample. The cell fluorescence was immediately recorded by flow cytometry with FACSort (Becton Dickinson,) in the FL-3 ( $\left.\lambda_{\text {em }}>650 \mathrm{~nm}\right)$ channel. Note that the percentage of PI positive cells found for control cells has been subtracted from that of treated cells. The fluorescence of EGFP was measured using $488 \mathrm{~nm}$ excitation wavelength $\left(\lambda_{\text {exc }}\right)$ and $520 \mathrm{~nm}$ of emission wavelength $\left(\lambda_{\mathrm{em}}\right)$ in the FL-1 channel. The results were expressed in terms of percentage of EGFP positive cells and PI positive cells. Ten thousand events were recorded from each sample.

\section{Internalization process of lipoplexes}

HeLa cells were incubated at $37^{\circ} \mathrm{C}$ with $0.5 \%$ PE-Rhodamine (Avanti Polar Lipids, Alabama, USA) labelled liposomes complexed with a fluorescein-labelled plasmid. The plasmid was labelled with Label IT fluorescein nucleic acid labelling (MIRUS, Madison, WI, USA) at 1:2 
reagent/pDNA weight ratio according to the manufacturer instructions. The complexes of DDSTU were prepared at a TU/P $=40$ ratio and the DMAPAP complexes at a N/P $=4$ ratio.

The intracellular fate of lipids and DNA was followed by confocal microscopy, with a Zeiss Axiovert 200 M microscope coupled to a Zeiss LSM 510 scanning device (Carl Zeiss Co. Ltd., Germany). The inverted microscope was equipped with a Plan-Apochromat $63 \times$ objective (numerical aperture $=1.4$ ) and with a temperature-controlled stage. To evidence presence of DNA in the nucleus, $1 \mu \mathrm{M}$ DRAQ5, a far-red fluorescent DNA dye (Biostatut Limited, UK), was added to the medium to stain the cell nuclei blue when we observed green spots in the nucleus. . Images were recorded with Carl Zeiss's software LSM Image Browser and were calculated with the public-domain software ImageJ. Each image was represented with $512 \times 512$ pixels of $0.28 \times$ $0.28 \mu \mathrm{m}^{2}$ each, and recorded with a line mode to reduce background noise (average on 2 scanning images). The acquisition of each image was performed with the CLSM's Meta mode selecting specific domains of the emission spectrum, i.e.

\section{RESULTS}

\section{Physico-chemical characterization}

Since the characterization of DDSTU and DMAPAP lipids has been previously studied $[9,12]$, here, we report only data corresponding to lipoplexes formulations used for the cellular studies. As shown by the agarose gel electrophoresis (figure 2A), the absence of DNA migration indicated that it was well compacted at TU/P ratio of 40 for DDSTU and N/P ratio of 4 for DMAPAP. Under theses formulations, both lipoplexes exhibited a size of about $200 \mathrm{~nm}$ (Figure 2A).

Then, the lipid phase transition of each type of lipoplexes was assessed as function of $\mathrm{pH}$ 
by using the emission wavelength of Nile Red incorporated in lipoplexes as described for SAINT complexes [16]. Figure 2B shows that a red shift of the Nile Red emission wavelength in cationic complexes occurred when the $\mathrm{pH}$ decreased, while no change was observed with thiourea complexes. These data showed that the thiourea lipid did not undergo a lipidic phase transition at acidic $\mathrm{pH}$ as it could be expected for uncharged lipids. Conversely, the red shift observed at a $\mathrm{pH}$ around 6 with cationic complexes indicates an environmental change of the fluorophore. This is related to a phase transition of DOPE present in cationic lipoplexes. Indeed, DOPE is known to undergo a phase transition at this $\mathrm{pH}$ upon the phosphate moiety protonation [17].

Figure 2 Physico-chemical parameters of lipoplexes. (A) Agarose gel electrophoresis of DNA complexed with DDSTU at TU/P $=40$ and DMAPAP at N/P $=4$ and lipoplexes size (nm). (B) Lipid phase transition determination. The maximal emission wavelength of Nile Red inserted in DDSTU or DMAPAP lipoplexes measured as a function of $\mathrm{pH}$.

\section{Transfection efficiency}

After physico-chemical characterization of lipoplexes, we assessed their transfection efficiency on B16 murine melanoma cell line, J774 murine macrophage cell line and two human cell lines, HeLa (epithelial ovarian carcinoma cells) and Eahy 926 (endothelial cells). Gene transfection performed on different cell lines indicated that the DDSTU complexes were able to transfect cells in presence of $10 \%$ serum. We could evidence a dose dependence of the transfection level on B16, Eahy 926 and HeLa cells. The luciferase level on the B16 cell line was underneath the one obtained with cationic lipoplexes in the same conditions of non aggregating complexes (Figure 3, N/P = 8, $* \mathrm{p}<0.05$ ). The luciferase level was slightly lower for neutral 
lipoplexes compared to cationic lipoplexes in the case of Eahy 926 cells. However the number of transfected cells was quite similar (around 50 to 60\%). For HeLa cells and J774, macrophage cells that are hard to transfect with cationic lipids [18], the transfection level mediated by thiourea and cationic lipoplexes was not significantly different (Figure 3). In absence of serum, similar results were obtained except for macrophages in which enhanced transfection efficiency was observed with the two types of lipoplexes (not shown). The best transfection results were globally obtained at TU/P ratio of 20 or 40 . The TU/P ratio of 40 was chosen for the following experiments. The cytotoxicity of lipoplexes was assessed by a MTT colorimetric assay on B16 cells, IC50 of DDSTU and DMAPAP lipoplexes was $29 \mu \mathrm{M}$ and $49 \mu \mathrm{M}$, respectively.

Figure 3. Transfection efficiency of lipoplexes. Luciferase expression obtained after $24 \mathrm{~h}$ transfection of B16, Eahy926, J774 and HeLa cells with DDSTU/DNA complexes at different $\mathrm{TU} / \mathrm{P}$ ratios in presence of serum. Data are expressed in $\mathrm{CPS} / \mu \mathrm{g}$ of protein content. The cytotoxicity of DDSTU and DMAPAP lipoplexes was assessed by a MTT colorimetric assay. Statistics were calculated with a t-unpaired test with Welch's correction $(*$ for $\mathrm{p}<0.05$, no sign means that data are not statistically different).

\section{Influence of temperature on the amount of cell-associated plasmid}

Kinetics of cell-associated DNA following incubation of HeLa cells with Cy5-labelled plasmid complexed by thiourea or cationic lipoplexes were evaluated at $4{ }^{\circ} \mathrm{C}$ and $37^{\circ} \mathrm{C}$ by flow 
cytometry (Figure 4). Data show that at $4^{\circ} \mathrm{C}$, the cellular binding of DNA complexed with thiourea liposomes was 5 to 6 times lower than that of DNA complexed with cationic liposomes. At $37^{\circ} \mathrm{C}$, the fluorescence intensity of cells incubated with both lipoplexes was 2 to 3 -fold higher than the one measured at $4{ }^{\circ} \mathrm{C}$. As for the binding at $4^{\circ} \mathrm{C}$, the amount of DNA complexed with cationic liposomes was 4.5 to 6-fold higher than that of DNA complexed with thiourea liposomes. The kinetics of cell-associated DNA indicate that the interaction of thiourea lipoplexes with cells appears to be faster than that of cationic ones. This suggests differences in terms of cellular association between these two types of lipoplexes.

Figure 4 Kinetics of cell-associated Cy5-labelled DNA complexed with DDSTU or DMAPAP lipids (dashed line) or $37^{\circ} \mathrm{C}$ (full line). HeLa cells were incubated at either $4^{\circ} \mathrm{C}$ (dashed line) or at $37^{\circ} \mathrm{C}$ (full line) for indicated times with $2 \mu \mathrm{g}$ of Cy5-labelled pDNA complexed with DDSTU lipoplexes $(\mathrm{TU} / \mathrm{P}=40)$ or DMAPAP $(\mathrm{N} / \mathrm{P}=4)$. The mean cell fluorescence intensity (a.u: arbitrary unit) was measured by flow cytometry. Data are mean of 3 separated experiments made in duplicate.

\section{Permeabilizing activity of lipoplexes}

We have previously observed that transfection efficiency, at low TU/P ratios, was significantly improved by addition of liposomal lipopolythioureas (data not shown). Moreover, thiourea lipoplexes do not tend to undergo a phase change at lower $\mathrm{pH}$. We wondered then if this lipid could destabilise the cell membrane. Thus, we first studied the permeabilizing activity of 
thiourea lipoplexes to small molecules such as propidium iodide (PI). Cells were incubated with lipoplexes and, at indicated times propidium iodide was added to the cell suspension, then the cell fluorescence-associated to PI was immediately recorded. As shown on figure 5, 100\% of cells were permeabilized (PI-positive cells) after15 minutes incubation with DDSTU lipoplexes whilst, $40 \%$ of cells were permeabilized with DMAPAP lipoplexes. In line with the DNA binding at $4^{\circ} \mathrm{C}$, the kinetic of permeabilization activity of thiourea was faster than that of cationic lipoplexes.

We further evaluated whether membrane permeabilization induced by DDSTU lipoplexes could allow the passage of small protein such as EGFP. For this purpose, a HeLa cell clone stably transfected with a plasmid encoding EGFP (EGFP-HeLa cells) was used.[19] The incubation of cells with DDSTU lipoplexes led to a rapid decrease of the number of EGFP-positive cells (Figure 5). Fifty and twenty percent of cells were EFGP-positive after $5 \mathrm{~min}$ and $30 \mathrm{~min}$ of incubation, respectively. These data are indicative of a high permeabilizing activity of these lipoplexes. By contrast, about $90 \%$ of cells were still EGFP positive after 30 min incubation with cationic lipoplexes indicating that these lipoplexes did not exhibit membrane permeabilizing activity.

Overall, these results demonstrate a strong membrane destabilisation activity of the DDSTU lipoplexes that permits the passage of low molecular weight molecule as PI and small protein of $27 \mathrm{kDa}$ as EGFP.

Figure 5 Fluorescence intensity of Propidium Iodide labelling of HeLa cells and of EGFP release from EGFP-HeLa cells induced by DDSTU lipoplexes $(\boldsymbol{\Delta})$ and DMAPAP lipoplexes ( $\boldsymbol{\bullet})$. Values are means of three independent experiments done in duplicate. 


\section{Internalization process and real time intracellular trafficking of lipoplexes}

Different internalization paths have been suggested for DNA complexes, such as actinmediated endocytosis [20], caveolae mediated endocytosis [6] or macropinocytosis[5]. Cells could take up thiourea lipoplexes by one of these pathways. To investigate, the efficient uptake route of these lipoplexes, transfection experiments were conducted in the absence and the presence of different inhibitors of endocytosis pathways (Figure 6). Methyl-beta-cylodextrine [2], sucrose [21] and EIPA [22] inhibit the caveolae-mediated endocytosis, clathrin-mediated endocytosis and macropinocytosis, respectively. The transfection efficiency of DDSTU complexes was reduced to approximately the same level (10-fold) by these inhibitors. By contrast, the influence of these inhibitors on the transfection efficiency of DMAPAP complexes was not similar. Indeed, sucrose and EIPA reduced by 100 -fold the transfection level whilst the effect of methyl-beta-cyclodextrine was comparable to that obtained for transfection by DDSTU complexes. These results tend to show that different ways are involved for DDSTU complex internalisation and transfection. For DMAPAP complexes, internalisation and transfection are favored by clathrin-mediated endocytosis and macropinocytosis while caveolae-mediated endocytosis seems to be involved in a lesser extent.

Figure 6 Influence of different endocytosis inhibitors on the transfection efficiency of lipoplexes. Luciferase expression of cells transfected with DDSTU/DNA (TU/P $=40)$ and DMAPAP/DNA $(\mathrm{N} / \mathrm{P}=4)$ lipoplexes in absence (control) or presence of different endocytosis inhibitors. Statistics 
were calculated with a t-unpaired test with Welch's correction $(* *$ for $\mathrm{p}<0.01$ and *** for $\mathrm{p}<0.005$, no sign means data are not statistically different).

Time lapse experiments were performed to follow the internalization process of the two types of lipoplexes. Studies were conducted on live cells with rhodamine-labeled liposomes and fluorescein-labeled plasmid. Various optical sections of cells were recorded for each time. Images shown correspond to mid optical sections to maximize the observation of events in the cytoplasm, as well as those close to the nuclei. One could observe that DDSTU complexes were strongly bound to the plasma membrane as shown by the typical staining of the cell periphery (Figure 7). Up to 10 min of incubation, most of plasmid was still complexed with DDSTU liposomes as indicated by yellow colored spots corresponding to the merge of red-labeled liposomes and green-labeled plasmid. From $16 \mathrm{~min}$ of incubation, one could observe a higher number of green spots corresponding to plasmid without or with low amount of liposomes beneath the plasma membrane and throughout the cytoplasm. After 20 min, some of these spots were found close to the nuclei and they were clearly found inside the nucleus after $30 \mathrm{~min}$. Concerning cationic lipoplexes, most of plasmid was complexed with DMAPAP when bound to the plasma membrane (yellow spots). In several cells, the number of green spots was lower than those observed with DDSTU and they were not localized close to the nucleus till $30 \mathrm{~min}$ of incubation. A clear presence of plasmids inside the nucleus was observed only upon at least 60 min. Consistently to flow cytometry analysis, it has to be noticed that the overall number of DMAPAP lipoplexes inside each cell was higher (at least five times more) than that of DDSTU lipoplexes. 
These observations validate the different behavior of these two types of vectors and indicate that in the thioureas-based lipoplexes, plasmids can be more quickly dissociated.

Figure 7: Real time confocal microscopy of lipoplexes uptake. HeLa cells were incubated with fluorescein (green) labeled plasmid DNA complexed either with rhodamine (red) labeled thiourea lipoplexes (A) or cationic lipoplexes (B). DRAQ5 was added in the medium to stain the cell nuclei (blue). Images were recorded on live cells as described in the Material and Methods section. Images shown correspond to representative images of analyzed cells. Zooms correspond to magnification of area delineated by the white rectangle on images recorded after 22 and 26 min incubation with DDSTU lipoplexes (A) and after $32 \mathrm{~min}$ and $60 \mathrm{~min}$ incubation with DMAPAP lipoplexes (B). Scale bars in A and B corresponds to $12 \mu \mathrm{m}$ and $15 \mu \mathrm{m}$, respectively. 


\section{DISCUSSION}

We developed a few years ago a neutral polythiourea lipid for gene delivery so as to avoid non specific elimination of the complexes from the blood. We expected these compounds to interact less efficiently with cells than the polyamine lipids because of their lack of cationic charges. The optimisation of the structure of these lipids [23] provided us with lipoplexes exhibiting high transfection efficiency on various cell lines in presence of serum. Here, we investigated the transfection process mediated by thioureas lipoplexes and compared it to the one mediated by cationic complexes. After characterising the complexes, we studied their kinetic of cell internalisation, their membrane permeabilizing activity, as well as DNA release into the cells.

The point that ought to be underlined is the fact that although thiourea and cationic lipoplexes gave a similar level of transfection, internalisation of the thiourea complexes was measured to be 6 times less efficient than for cationic ones. Given the non ionic nature of the thiourea lipoplexes, this low internalization could be expected. Therefore, the similar transfection efficiency means that either DDSTU complexes were internalized via a different process as compared to DMAPAP complexes or that they could release DNA more efficiently.

To evaluate the first point, we looked at the effect induced by the thiourea lipoplexes on cellular membrane. Indeed, as the complexes were not subject to lipid phase change as a function of the $\mathrm{pH}$, we wondered how the thiourea lipoplexes did interact with the membranes and released DNA. These lipoplexes obviously interact rapidly with the plasma membrane. We followed the permeabilisation effect of the two types of lipoplexes. In contrast to cationic complexes, we demonstrated that thiourea lipoplexes exhibit a membrane permeabilizing activity allowing the passage of small molecules, such as propidium iodide, and also small proteins, such 
as EGFP. A mechanism based on detergent membrane destabilisation might then be suggested to explain both membrane interaction and DNA release by thiourea lipoplexes. [24]

The intracellular fate of thiourea and cationic lipoplexes was also evaluated. Using different endocytosis inhibitors, we could show that the internalization of both types of complexes involves several pathways. Inhibitors are obviously not completely specific and can induce some secondary effects which can impair the interpretation of our transfection results; however a trend seems to appear involving multiple paths for DDSTU complexes and mostly clathrin-mediated endocytosis and macropinocytosis for DMAPAP complexes. Moreover, this result is not surprising. Indeed, an extensive review of uptake pathways in non viral gene delivery has reached the conclusion that the contribution of each endocytic path is not yet well understood and depends on the nature and characteristics of the gene vectors [25]. To evaluate the second point, we followed DNA release from the complexes at $37^{\circ} \mathrm{C}$ and observed that a higher amount of free plasmid could be found after 10 minutes incubation with thiourea complexes as compared to incubation with the cationic lipoplexes. Thiourea lipids have less affinity for DNA than cationic lipids as shown by gel retardation experiments. Indeed for the same amount of plasmid, 5 times more thiourea lipids than cationic lipids are needed to fully compact DNA. The interaction between thiourea lipid and DNA is believed to occur thanks to H-bond interaction between the thiourea functions of the lipids and the phosphate functions of DNA[26]. This interaction is less efficient than ionic interactions as more lipid is required to interact with DNA even though the supramolecular structure tends to stabilise the assembly, as DNA was shown to be protected from serum degradation in these structures [9]. Hence, intracellular plasmid release from thiourea lipoplexes might be facilitated by weaker interactions between the lipid and plasmid DNA as compared to ionic bonding involved in cationic lipoplexes. This could explain why thiourea 
complexes could transfect efficiently despite a lower internalisation rate compared to cationic lipoplexes.

\section{CONCLUSION}

Finally, our data evidences two striking differences between thiourea and cationic lipoplexes concerning their permeabilizing activity on the plasma membrane and the release of DNA inside the cells. Indeed, DDSTU complexes were shown to permeabilise the membrane to small proteins. Flow cytometry and real time confocal microscopy experiments also allowed us to conclude that despite being less taken up by cells, DDSTU lipoplexes delivered more rapidly DNA in the nucleus as compared to cationic lipoplexes. Overall, these experiments show that the internalisation pathway and subsequent intracellular trafficking are of the utmost importance for efficient gene delivery. 


\section{REFERENCES}

1. Wasungu L, Hoekstra D Cationic lipids, lipoplexes and intracellular delivery of genes. Journal of Controlled Release 2006; 116: 255-264.

2. Zuhorn IS, Kalicharan R, Hoekstra D Lipoplex-mediated transfection of mammalian cells occurs through the cholesterol-dependent clathrin-mediated pathway of endocytosis. Journal of Biological Chemistry 2002; 277: 18021-18028.

3. Hoekstra D, Rejman J, Wasungu L, et al. Gene delivery by cationic lipids: in and out of an endosome. Biochemical Society Transactions 2007; 35: 68-71

4. Rejman J, Conese M, Hoekstra D Gene transfer by means of lipo- and polyplexes: Role of clathrin and caveolae-mediated endocytosis. Journal of Liposome Research 2006; 16: 237-247.

5. Khalil IA, Kogure K, Futaki S, et al. High density of octaarginine stimulates macropinocytosis leading to efficient intracellular trafficking for gene expression. Journal of Biological Chemistry 2006; 281: 3544-3551.

6. Rejman J, Bragonzi A, Conese M Role of clathrin- and caveolae-mediated endocytosis in gene transfer mediated by lipo- and polyplexes. Molecular Therapy 2005; 12: 468-474.

7. Buhlmann P, Nishizawa S, Xiao KP, et al. Strong hydrogen bond-mediated complexation of $\mathrm{H}_{2} \mathrm{PO}_{4}{ }^{-}$by neutral bis-thiourea hosts. Tetrahedron 1997; 53: 1647-1654

8. Tranchant I, Mignet N, Crozat E, et al. DNA complexing lipopolythiourea. Bioconjugate Chemistry 2004; 15: 1342-1348.

9. Leblond J, Mignet N, Largeau C, et al. Lipopolythioureas: A new non-cationic system for gene transfer. Bioconjugate Chemistry 2007; 18: 484-493.

10. Leblond J, Mignet N, Largeau C, et al. Lipopolythiourea transfecting agents: Lysine thiourea derivatives. Bioconjugate Chemistry 2008; 19: 306-314.

11. Sakurai F, Inoue R, Nishino Y, et al. Effect of DNA/liposome mixing ratio on the physicochemical characteristics, cellular uptake and intracellular trafficking of plasmid DNA/cationic liposome complexes and subsequent gene expression. Journal of Controlled Release 2000; 66: 255-269

12. Thompson B, Mignet N, Hofland H, et al. Neutral postgrafted colloidal particles for gene delivery. Bioconjugate Chemistry 2005; 16: 608-614. 
13. Chen TR Insitu detection of mycoplasma contamination in cell-cultures by fluorescent hoechst-33258 stain. Experimental Cell Research 1977; 104: 255-262

14. Escriou V, Carriere M, Bussone F, et al. Critical assessment of the nuclear import of plasmid during cationic lipid-mediated gene transfer. Journal of Gene Medicine 2001; 3: $179-187$

15. Scudiero DA, Shoemaker RH, Paull KD, et al. Evaluation of a soluble tetrazolium formazan assay for cell-growth and drug sensitivity in culture using human and other tumor-cell lines. Cancer Research 1988; 48: 4827-4833

16. Wasungu L, Stuart MCA, Scarzello M, et al. Lipoplexes formed from sugar-based gemini surfactants undergo a lamellar-to-micellar phase transition at acidic $\mathrm{pH}$. Evidence for a non-inverted membrane-destabilizing hexagonal phase of lipoplexes. Biochimica Et Biophysica Acta-Biomembranes 2006; 1758: 1677-1684.

17. Koltover I, Salditt T, Radler JO, et al. An inverted hexagonal phase of cationic liposomeDNA complexes related to DNA release and delivery. Science 1998; 281: 78-81

18. Mounkes LC, Zhong W, Cipres-Palacin G, et al. Proteoglycans mediate cationic Liposome-DNA complex-based gene delivery in vitro and in vivo. Journal of Biological Chemistry 1998; 273: 26164-26170

19. Swenson ES, Price JG, Brazelton T, et al. Limitations of green fluorescent protein as a cell lineage marker. Stem Cells 2007; 25: 2593-2600.

20. Bausinger R, von Gersdorff K, Braeckmans K, et al. The transport of nanosized gene carriers unraveled by live-cell imaging. Angewandte Chemie-International Edition 2006; 45: $1568-1572$.

21. Sahay G, Batrakova EV, Kabanov AV Different Internalization Pathways of Polymeric Micelles and Unimers and Their Effects on Vesicular Transport. Bioconjugate Chemistry 2008; 19: 2023-2029.

22. Nakase I, Niwa M, Takeuchi T, et al. Cellular uptake of arginine-rich peptides: Roles for macropinocytosis and actin rearrangement. Molecular Therapy 2004; 10: 1011-1022.

23. Leblond J, Mignet N, Leseurre L, et al. Design, synthesis, and evaluation of enhanced DNA binding new lipopolythioureas. Bioconjugate Chemistry 2006; 17: 1200-1208. 
24. Sato H, Felix JB Peptide-membrane interactions and mechanisms of membrane destruction by amphipathic alpha-helical antimicrobial peptides. Biochimica Et Biophysica Acta-Biomembranes 2006; 1758: 1245-1256.

25. Khalil IA, Kogure K, Akita H, et al. Uptake pathways and subsequent intracellular trafficking in nonviral gene delivery. Pharmacological Reviews 2006; 58: 32-45.

26. Jubian V, Dixon RP, Hamilton Ad molecular recognition and catalysis - acceleration of phosphodiester cleavage by a simple hydrogen-bonding receptor. Journal of the American Chemical Society 1992; 114: 1120-1121

The authors state that no potential financial or personal conflicts exist concerning this manuscript 